Southern Illinois University Carbondale OpenSIUC

9-2010

\title{
Hunting in the Shadows for Savings: Reevaluating Standing Orders
}

\author{
Roger L. Cross \\ Southern Illinois University Carbondale, rcross@lib.siu.edu
}

Follow this and additional works at: http://opensiuc.lib.siu.edu/morris_articles

Published in The Bottom Line: Managing Library Finances, Vol. 23, issue 3 (2010) at 10.1108/

08880451011087658

\section{Recommended Citation}

Cross, Roger L. "Hunting in the Shadows for Savings: Reevaluating Standing Orders." (Sep 2010).

This Article is brought to you for free and open access by the Morris Library at OpenSIUC. It has been accepted for inclusion in Articles by an authorized administrator of OpenSIUC. For more information, please contact opensiuc@lib.siu.edu. 


\section{Introduction}

Hidden costs and unexpected expenses are unpleasant surprises for anyone on a budget, or managing a budget. Ideally, a budget rationalizes the expenditures/funding process so that every cost is covered by an amount dedicated to that particular line. Among non-profit organizations and public institution like libraries, the budget should zero-out at fiscal years' end. State institutions are often prohibited from carry-over funding, and can impose stringent restrictions on financial mechanisms like vendor prepaying to a small percentage of the total materials budget. In difficult times with dwindling resources affecting so many state institutions it becomes all the harder to justify maintaining contracts for the automated delivery of books known as Standing Orders. I want to make it clear what I mean by Standing Orders from the start and distinguish them from other materials received by the library. First, while they resemble approval plans the two terms designate different things. Approval plans are set up with a vendor, or vendors, to deliver books, scores, or other materials. Usually the funds used for approval plan books come from the same pot of funds as books selected by librarians or faculty. Approval plans are not the same as Standing Orders unless the plan is set up to deliver Standing Orders (in which case they are part of an approval plan). Nor are standing orders journals and are not shelved with journals. Standing Orders, in the sense used here, are predominately books that share a serialized title and are thus charged to the library as a serial. A successful hunt for standing orders will begin in the serials account. The first step in isolating Standing Orders will be to strip away all the titles in the serials account that are actually journals. It is the purpose of this paper to suggest ways to undertake this process.

\section{The Problem with Standing Orders}

Standing Orders are the remnants of an earlier period of library acquisition. They were rational mechanisms to ensure completeness of a library's holdings at a time when many libraries actually strove 
for completeness. The librarian managing the collection and the budget could set up a standing order on a particular subject matter and be assured that, barring theft or damage, the multivolume series would not have unexplained and annoying gaps or missing volumes. Standing orders were frequently requested by a particular department or even faculty member. Unfortunately, they may still be blindly delivering volumes on an obscure or highly specialized subject matter decades after the originating faculty member and librarian have retired. The problem with standing orders is that, once they are set up, the entire library process from receiving through shelving is automated. Regaining control of the budget requires reexamining all the contracts started and set in motion years ago. There is no question that Standing Orders still are a valuable tool, but they need to be seriously re-evaluated for their usefulness to the library and collection.

I have worked at both a small liberal arts college and at an ARL library, and in both institutions I have reevaluated the library's standing orders. Working in a small school library environment with its limited budget constantly kept me seeking areas to trim within the materials budget. Much of what I found in need of cutting, or at least possible to cut, were the standing orders that had lost relevance to our institution. When I joined SIU the need to cut expenses was even greater as the state budget foundered and libraries faced the threat of mid-year $10-30 \%$ rescission. In an environment where funding is so scarce that all materials' acquisition is halted, the unexpected arrival of standing order invoices for thousands of dollars is most unwelcomed. Ideally the library should anticipate any serial's arrival and taken steps to prevent or delay it. But it is exactly the uncertainty surrounding many Standing Orders that make them so difficult to manage.

Standing Orders still serve a function, but one I would argue that has diminished over time. I would never advocate eliminating all standing orders because doing so would inevitably lead to gaps in coverage for certain kinds of monographs. But there are three points to keep in mind when thinking 
about Standing Orders. First, they are a contract, a multiyear contract, that will generate titles that must be paid for. Second, Standing Orders can, and often will, outlive the career span of the average librarian, indeed perhaps several generations of librarians. The university might have passed through multiple incarnations; it could have gone from a teacher college to a research university; a school of agriculture to one of the premier institutions of computer and electrical engineering in the country -- but in all that time the standing order set up, say, circa 1963 continues to deliver book and invoice. This is why point three is so essential to understand: Standing Orders are often books that due to being "serialized" will most likely not be paid for from the monograph material funds, but from the serials fund. It is this dual nature, I believe, that makes them so difficult to locate and evaluate in a budget. Libraries can, and do, compartmentalize between various types of orders; monographs, serials, contractuals. Anything that straddles two or more of the compartments can fall into a grey zone and be overlooked. It is this dual nature of being serialized books that can protect them for decades during economic hardships and rounds of cancellations.

As digital resources have come to demand a greater share of the material budget, the book budget at SIU has declined by around half over the past decade. But during this time standing orders continued to arrive since they were not a part of the monograph budget and were not affected by declining book funds. Then, when serial cuts began to occur standing orders once more largely got a pass since they aren't journals and rarely rise at the inflationary journal rates. Further hampering the identification and evaluations of Standing orders in large libraries is that staff are often also as compartmentalized as is the budget. The Acquisition department for monographs can be separate from those who deal with serials, and both separated from digital management.

The shadowy dual-nature of Standing Orders means, in my experience, that tracking them down and evaluating their role in the collection is initially very labor intensive. Among small libraries with few 
librarians and a small number of staff, much of the work must be undertaken, from start to finish, by one individual. In large University libraries there is a need for cross-departmental cooperation and coordination, but even then it can be useful for someone to serve on "point." The rewards of such an evaluation, however, can be significant. During my first year here at SIU I worked with Acquisitions, the budget office, another collection development librarian, and numerous other staff and faculty members to identify and evaluate all available data on our standing orders. The end result was that at year's end we cut at least $\$ 50,000$ of standing orders. I say "at least" since the true savings will probably never be known for the reasons I raise below.

\section{The Process}

Unfortunately I have not found a reliable method of pulling Standing Orders out of the shadows that does not involve creating a stand-alone database. At the small college library where I worked this meant index cards in a box; at SIU this meant the creation of a spreadsheet that spanned multiple screen widths with hundreds of entries. Nor did I find much in the literature on Standing Orders as treated here that offered any short cuts to the stand alone spreadsheet. Thus, there will be a considerable amount of set-up time, but once titles are identified and added to the database the work load dramatically decreases. Maintenance, even over many years, is much easier once the initial database is populated. Small libraries have the advantage of fewer layers to negotiate since often the same person who handles collection development works closely with, or actually is, the person who handles invoices, budgets, cataloging and even electronic resource management. But small libraries face their own challenges. Creating and filling the spreadsheet may seem such a daunting task for one person that may hesitate to begin, but having been through it, I can offer tips on how such a major task can be undertaken. 
The first step is to create and populate a spreadsheet with all the titles listed under the "serials" account. The spreadsheet we created was populated mostly from three sources: our online electronic journal management service; our book vendor; and the integrated library system, the ILS. Unfortunately, titles that began before the advent of electronic library systems and to which the library subscribed directly with the publisher were still overlooked, I am sure. Still, the vast majority were identified and listed on our spreadsheet.

Though terminology can vary by institution, the database will need certain fairly universal headers and columns like title, publisher and some invoice number record. Conversely there are fields that may seem essential, but in our case, proved absolutely superfluous. One such item for us was the initial subscription date. Since we had changed our ILS in 2003, and since the new system was unable to communicate with the old system, every title we held began in 2003 or after according to our ILS. There were admittedly numerous columns in our spreadsheet that simply served little to no purpose. Therefore I would like to highlight the columns we found useful when it was time to evaluate our contracts for standing orders. I would suggest that the first step taken once the serials database is complete is to remove all periodicals. What is left will most likely be Standing Orders.

The database we created and used for actual evaluation had the following basic features: Serial Title, Location, Format, Frequency, Price, and when data was available, Usage or check-outs.

\section{Insert Table here}

In the above table each line represents some facet of our returns, and each heading, though they may seem fairly self-evident, needs comment: 
Serial Title - I suspect the category Serial Title was created by catalogers and is just something the rest of us have to live with. Whatever its origins it will group the periodical The Rolling Stone alongside the books of the Medieval \& Renaissance Texts \& Studies series. It is an umbrella term.

Price - The annual price of the series is recorded in the final column with the exception of those titles that returned a $\$ 0.00$ as their total. The lines with $\$ 0.00$ for price represent a particularly troublesome kind of Standing Order that arrive "irregularly" and will be treated in that section below. It is the fact that so many titles had an unrecorded price that makes it impossible to determine absolutely the total cancelation value. We cut $\$ 50,000$ plus whatever the cost of titles might have been in the future for the $\$ 0.00$ lines.

Location, Format, and Frequency are perhaps the three most important headers for determining what is the true type of the materials in question. They also demonstrate why Standing Orders can be so difficult to track.

The first two items on the table above are examples of important difference between classes of Standing Orders. The title "Humanities" is a print quarterly shelved with other periodicals; it is a journal and should be removed from the list. "Studies on Southeast Asia Series," on the other hand, are books shelved among the general book collection, not a periodical at all. This is an example of a serialized title of books covering a general subject area. Indeed, all items with location listed as Gen-Coll (General Collection) are books. The third title on the table, Medievalia et Humanistica is an example of an annually received title placed in the general collection. Roughly put, these kinds of standing orders are yearbooks, arriving at a set time and shelved in a set order. Thus it is a title that either the library can either decide to continue without gaps in coverage, or it is a title the library can cancel if it no longer serves a significant audience (we cancelled our subscription). 
This process becomes even more important as more of these yearbooks go online as package deals. If you have a digital package for Annual Review you may need to reconsider maintaining a print subscription. This will of course raise the issue of digital access versus the permanence of print, but that is not an argument for this paper. During in the process of reviewing Standing Order titles, unfortunately, we quickly found that yearbook types were not the majority types of Standing Orders the library received. The regular annuals, bi-annuals, quarterly, etc., accounted for between a fourth to a third of our Standing Orders contracts while the majority did not arrive on any set schedule.

"Location" served to distinguish between book and journal titles. It did not, however, prove sufficient in our review to determine the true nature of the serial title, which is why "format" and "frequency" were important. We quickly discovered was that Standing Orders were classified in two different ways; the first, rather redundantly, were "standing orders" of yearbooks, annuals, bi-annuals and the like, while the second type were classified as "scatters." The exact name of the latter type may be unique to SIU, but I doubt the distinction will prove unique.

The distinction between the types is that we receive standing orders, sequentially numbered or unnumbered, that go on the shelf side-by-side. These are the redundantly termed "standing orders." It is rare for this class of titles to become a true shadow title. The other class of titles, sequentially numbered or unnumbered, are termed "scatter." Scatter are volumes classified by the subject of each particular volume in the set. These types of titles can, and do, end up shelved by individual call numbers bearing no relation to previous or future volumes of the series; such a title is "Cambridge Studies In Medieval Life \& Thought." This is a numbered series that has not been shelved in our library in sequential order, and over just the past five years volumes were shelved under the LC call numbers DP125 (History of Spain); BX2436 (Christian Denominations); JX1641 (International law) and BR750 (Christianity) just to name a few. 
Were I asked how to immediately make an impact on library finances through reevaluating Standing Orders, my first advice would be to cancel "scatter" titles. This is not a statement about the content, but an issue of collection development and acquisitions. At one time Religion was a major at SIU, but no longer. Thus the automated addition of book titles dealing with specialized treatment of Medieval European Christianity is no longer warranted. Likewise, though SIU has both a Law and Medicine schools, each has its own libraries and their own funds. The general library, therefore, should not have in place an automated system that places these subjects on our shelves. To cancel a standing order for "scatter" titles is not like cancelling an encyclopedia midway through its publication. Standing orders are immensely useful for collecting sets, the real question is whether every individual volume under an umbrella title is any different than any other title published. The works may come from Oxford, Cambridge, Princeton or wherever, but we don't generally add titles simply based upon their publisher. We evaluate, in collection development, individual titles in order to determine whether it is appropriate for our institution. If you have a book vendor you can "hedge your bets" by transferring all scatter titles to slip titles. This keeps you aware of future volumes publications without necessitating that you are buying each title and it also transfers the cost of the title from Serials to Monographs.

A further trouble spot of many titles listed on the above table is frequency of arrival. Titles that arrive on an "irregular" schedule by definition guarantee you will not be expecting them. These are the titles that arrive whenever the publisher decides a particular volume or volumes is finished and ready for print. This type of Standing Order can be a particular problem for small schools where the sudden appearance of an invoice for three or four very expensive titles can seriously skew budget allocations. The situation is especially irreversible if receiving, stamping and cataloging all work independently. Once a work has gone through these channels, I have found no way to return them. 
The problem with "irregular" titles is clear for anyone who has ever searched for Volume 1 of the "Handbook of North American Indians." This series began its publication in 1978 and is still missing several of the proposed 20 volumes. And while the "Handbook of North American Indians" as a government publication is not completely apt, its dilatory publication schedule is by no means unique. We found that numerous titles reported a price of $\$ 0.00$ because it had been so long since we had been billed for them that they no longer in our budget records. In fact, a very beneficial by-product of the Standing Order review is the removal of "dead-letter" titles that just complicate and clog serial holdings records. In the course of the Standing Order review we found numerous titles from publishers and countries long gone. It is highly unlikely that we will ever receive promised volumes of any East Germany serial or those from any other part of the old Soviet Bloc. In cases where the country or publisher no longer exists we first double-checked to be sure a new publisher had not picked up the series, and if not, removed them from our active serials' list.

Other immediate clean-ups we were able to do in the process of creating the spreadsheet included removing titles that had moved from print to digital and titles that had been delivered in an obsolete format (when the library no longer provides work stations with dedicated CD-ROM software, this format in the library becomes obsolete).

The conclusion I have drawn, having worked in both large and small institutions, is that while the larger schools need diligence in monitoring irregulars, smaller schools might be better served canceling them almost altogether. I realize this risks having sporadic or coverage gaps, but I am just not certain that the risk nullifies the obvious benefits. For me the issue is one of automation versus selection. Whether we allow publishers to stock our shelves or whether we choose to stock them ourselves.

The last suggestion I would make, and one I am sure will make the most negative impact, is the consideration of what our patrons actually use. The internet has unquestionably rendered many types of 
titles semi-obsolete. This is true especially of many kinds of reference works and dictionaries. If your institution truly needs to cut costs, and deselecting Standing Orders is one of the avenues you have selected, then I doubt you can avoid seriously reviewing usage statistics. If the serials are books that can be checked out like books, then circulation should be able to pull the usage records. If the past several years of records show no usage of a title, no matter how revered it might be or for how long the library might have subscribed to it, you may just have to cut it because users are now finding this information online. Whatever the cause, if the usage is " 0 " the question becomes, is this a necessary expense?

\section{Conclusion}

A complete review of Standing Orders requires a significant amount of initial work that will undoubtedly require input and data from a variety of sources within the library organization. I have tried to provide a start for the review of Standing Orders for all those who want to save money, or just keep their active list current. Cutting Standing Orders is not likely to save a failing budget. It will not reverse serious decline in materials' allocation. But I would argue that it is worthwhile for the following reasons: it rationalizes the system by imposing a structure on a significant grey area of the materials budget and of collection development. It avoids surprises of the irregular type, and it is important in clearing dead letter entries from the active list. This in turn narrows the amount of material that would be needed to wade through in future, further, assessment of holdings. The latter is especially important when you need to impose across the board budget cuts quickly, such as when you receive word that you must quickly slash a total of $1 / 5$ of the materials budget. But that is a topic for a different article. 